\title{
DEVELOPING ONLINE PRACTICE TESTS TO CHECK THE ACQUISITION OF IDIOMATIC EXPRESSIONS WITH ANIMALS
}

\author{
Vanya IVANOVA, Gergana PETKOVA \\ University of Plovdiv "Paisii Hilendarski", Medical University - Plovdiv \\ Email: vantod@uni-plovdiv.bg ; gi4e82ap@abv.bg
}

\begin{abstract}
Idiomatic expressions, a large number of which refer to animals, are widely used in English since they tend to add color to the language and make everyday speech more interesting and exciting for native speakers. However, these expressions pose difficulties for learners of English as their meaning is not deductible from the meanings of the words comprising it. Furthermore, the meaning may not have any relation to the animals that they feature or there may not be a correspondence of similar expressions in the learners' mother tongues. Therefore, strategies to facilitate learning are needed and some of them, which can help students remember idioms more easily, are described in this article. Emphasis is placed on online practice tests, which check the acquisition of idiomatic expressions and facilitate their longterm retention. Practice tests are designed by the teacher and done by students on their personal computers or mobile phones at their own convenience. Also, some criteria specifically developed to enhance test construction are listed together with typical test questions based on them. Examples of different tasks are presented to illustrate the process of test creation. Finally, an appendix of some of the most commonly used idiomatic expressions with animals is included.
\end{abstract}

KEYWORDS: practice tests, online tests, self-study, test construction, criteria, idioms, animals

\section{Introduction}

Idiomatic expressions are phrases used in our daily lives that have a specific meaning, which is not deductible from the meanings of the words comprising it. They can add color and make everyday speech more interesting for native speakers; however, idioms often pose problems to learners of foreign languages since their literal translations can be rather confusing, vague, or they may make no sense at all. For example, if someone is pulling your leg, they are not physically attacking you but are making fun of you, if you get somebody's goat you are not stealing a domestic animal but irritating someone, or if your dogs are barking you may not have dogs at all but your feet are hurting. Idioms contain information about the history and culture of a country and broaden learners' understanding of the foreign language. There are an estimated 25,000 idioms in the English language and many of them feature animals. Hence, it is important to raise awareness about them and incorporate exercises based on idioms with animals in the foreign language education.

When students are presented with a large amount of new information, it is necessary to use techniques which help them remember it more easily. There are different ways to reinforce the process of learning. Among others, we can mention the following (Dunlosky, 2013, p. 13):

- $\quad$ Practice testing (self-testing) - taking practice tests over the material to be learnt;

- $\quad$ Distributed practice - implementing a schedule of practice that spreads out study activities over time;

- $\quad$ Interleaved practice - implementing a schedule of practice that mixes different kinds of problems, or a schedule of study that mixes different kinds of material, within a single study session;

- $\quad$ Elaborative interrogation - generating an explanation for why an explicitly stated fact or concept is true;

- Self-explanation - explaining how new information is related to known information, or explaining steps taken during problem solving;

- $\quad$ Rereading - restudying text material again after an initial reading;

- Highlighting and underlying - marking potentially important portions of materials that need to be learned while reading;

studied;

- Summarization - writing summaries (of various lengths) of texts that have to be 
materials;

or listening.

Keyword mnemonic - using keywords and mental imagery to associate verbal

Imagery for text - attempting to form mental images of text materials while reading

The authors (Dunlosky et al., 2013, p. 26) have carried out extensive research on the techniques in a range of conditions, for a range of learner ages and levels of prior knowledge. As a result, two techniques have come out as clear winners: practice testing and distributed practice.

Practice testing refers to any form of testing for learning, which a student is able to do on their own. Examples of this technique include practising recall through flash cards, or completing practice problems or tests. Regarding the number of tests necessary to accomplish the goal and their timing, the authors concluded that multiple practice tests are most beneficial in combination with distributed practice, i.e. when they are spaced in time, rather than crowded in, one after another (Karpicke, Blunt, 2011, p. 1).

In line with these results, we have been using online practice tests in English at the University of Plovdiv for seven academic years. These tests are developed by the teacher based on the precise material studied during seminars. The objective of incorporating self-study tests in English language learning is to enhance the educational achievements of students and help them to remember and practice what they have learned. These tests are administered online every week to provide students with an opportunity to consolidate their knowledge and review their progress in their own place and time using personal computers or mobile devices. It is important that self-study tests include a comparatively small amount of the learning material and that they are conducted shortly after students have been exposed to the content (Ivanova, 2014, p. 167).

Some advantages of self-study tests are that they provide teachers with essential information, which can be used to make decisions about instruction and student grades, and they require students to invest comparatively little time into them. Since each practice test has the same structure and method of scoring and it is done on a regular weekly basis, students get used to the types of activity. In addition, students obtain their test results immediately except for the open question(s) score, which is added after the teacher has evaluated the texts, and this enables tests to be used not only to evaluate knowledge and skills but also to reinforce them.

Practice tests can be designed to test exclusively idioms with animals or they can incorporate these idioms with other relevant study materials. To construct self-study tests, 5 criteria have been formulated and followed in accordance with Bloom's taxonomy (Ivanova, Terzieva, 2016, p. 58). According to Bloom, there are six main levels in the cognitive domain that are hierarchically arranged on the principle "from simple to complex": knowledge, comprehension, application, analysis, synthesis, and evaluation. These levels can be considered as varying in degree of difficulty - learning at the higher levels depends on having attained prerequisite knowledge and skills at the lower levels (Bloom, 1956, p. 44).

Criterion I. Reproduction of information.

Criterion II. Understanding the meaning of a word, expression, or a phraseological unit and finding a match.

Criterion III. Detection of errors in various contexts.

Criterion IV. Analysis of the lexical and grammatical items of a sentence.

Criterion V. Text creation.

\section{Test construction based on idioms with animals}

We will illustrate the applications of these criteria with different types of test questions based on idioms with animals (Wyatt, 2006, p.7).

Since Criterion I (reproduction of information) is the lowest levels in the cognitive domain, the usual type of test questions used for it are multiple choice questions to find out if students remember the form of the idiomatic expressions correctly.

Examples (the correct answers are underlined): 
Choose the correct word to complete the idiomatic expressions in the sentences.

1. I got it straight from the .........'s mouth that he is going to propose to her tonight!

a. horse

b. pig

c. cat

d. bird

2. You have been fighting again! Your clothes look like something that the .......... dragged in!
a. rat
b. cat
c. $\operatorname{dog}$
d. pig

3. All his warnings were water off a .........'s back - she didn't pay attention to them.

a. rat

b. goose

c. duck

d. whale

4. He was like a with two tails when he got his visa to America.

a. rat

b. cat

c. $\operatorname{dog}$

d. horse

5. Your bad news really cooked my Now I can't go away for the weekend!

a. fish

b. chicken

c. duck

d. goose

Criterion II. (understanding the meaning of a word, expression, or a phraseological unit and finding a match) also incorporate multiple choice questions to match idioms with their definitions, and, wherever possible, synonyms and antonyms, as well as True or False and cloze questions.

Definitions: Match the idioms to their meanings.

1. a ratbag

a. a person who is unpleasant with other people

b. a person who looks very untidy

c. somebody with a high opinion of himself/herself

d. somebody who likes secrets and doesn't share

2. a white elephant

a. an important day which is pleasant to remember

b. a symbol of purity and innocence

c. a little lie that you tell in order not to hurt other people's feelings

d. something useless and expensive that you can't get rid of

3. She wouldn't say boo to a goose.

a. She doesn't like animals. 
b. She is afraid of all farm animals.

c. She is very quiet and shy.

d. She is a very proud person.

4. Our boss is a cold fish.

a. Our boss likes wearing warm clothes.

b. Our boss isn't very friendly.

c. Our boss likes swimming in cold water.

d. Our boss likes walking outside no matter how cold the weather is.

5. He is hen-pecked.

a. His wife gives him orders.

b. He lives on a farm.

c. He doesn't eat meat.

d. He is not married.

Synonyms: Select the idiom which has a similar meaning to the given one.

1. He thinks he is the bee's knees. He is

a. the dog's dinner

b. a dark horse

c. a cold fish

d. the cat's whiskers

2. I haven't seen you in a coon's age. I haven't seen you in

a. a pig's eye

b. the doghouse

c. donkey's ears

d. bird's-eye view

Antonyms: Select the idiom which has the opposite meaning to the given one.

1. This looks like something that the cat dragged in. It is

a. hen-pecked

b. as clean as a hound's tooth

c. as crooked as a dog's hind leg

d. as sick as a dog

2. My neighbor is pigheaded. He is

a. a fly on the wall

b. like a dog with two tails

c. a dog in the manger

d. as meek as a lamb

The test questions referring to Criterion III. (detection of errors in various contexts) are usually multiple choice ones to choose the part of the sentence which contains a spelling or grammar mistake and True or False to determine whether the sentences are free of lexical or grammatical errors or not.

Choose the part of the sentence which contains a spelling or grammar mistake.

1. After years in the army I don't think my brother will change his sleeping habits - you can't to teach an old dog new tricks!
a. I don't think
b. will change 
c. can't to teach

d. an old dog

2. The mother was watching her little girl like an hawk to prevent her from falling.

a. was watching

b. like an hawk

c. to prevent her

d. from falling

3. The elephant in the room that nobody wanted to see were money.

a. the elephant

b. the room

c. wanted to see

d. were money

4. I thought I should report the incident but then I decided to let sleeping dogs lying.

a. thought

b. should report

c. decided to let

d. sleeping dogs lying

5. After a night out with my friends we all needed the hair of the dog that bited us.

a. a night out

b. needed

c. the hair of the dog

d. bited

Mark the sentences as True if they are free of lexical or grammatical errors, or False if you have found a mistake.

1. My little niece is so shy that she wouldn't say boo to a goose.

a. True

b. False

2. He's been working late in his office for weeks so his wife smells a rats.

a. True

b. False (a rat)

Criterion IV. (analysis of the lexical and grammatical items of a sentence) refers to the use of idioms in context. The most common types of test questions for this criterion are multiple choice ones to select a sentence which most accurately explains the meaning of a given idiom used in context, or to choose the correct grammatical form of a verb. Also, short-answer test tasks are designed to write the most appropriate word(s) or expression(s) or grammatical form in a sentence.

Select the sentence which most accurately explains the meaning of the given one.

1. If you don't want to lose your job, you have to take the bull by the horns.

a. If you wish to keep your job, you should become a bullfighter.

b. To maintain your employment, you must attack difficult problems fearlessly.

c. If you don't desire to continue work, you can deal with risky situations bravely.

d. In order to save your job, you need to avoid problems at all costs.

2. You can start without me; I'm just going to see a man about a dog. 

owner.

a. You can begin immediately because I am going to discuss some dog problems with its

b. You needn't waste time waiting for me as I'm going to take a short nap.

c. Please start without waiting for me, I'm going to the washroom and will be back soon.

d. It's ok for you to begin without me since I have a business meeting to attend.

3. The salesman who sold me a television set is as crooked as a dog's hind leg.

a. The salesperson I bought my TV from is very dishonest.

b. The vendor who sold me a TV set has curved legs.

c. The dealer that I purchased my television from is foul-smelling.

d. The seller who traded me a TV set is a sincere and trustworthy man.

4. My neighbor wanted to borrow some money from me but he was barking up the wrong tree.

a. The guy next door asked rudely for some money like a dog barking at me.

b. My next door neighbor wished to take a loan from me but I don't trust him because he doesn't like dogs.

c. The man living next door needed to borrow some money but I refused because his clothes were very scruffy and dirty.

d. My neighbor asked me to lend him some money but he asked the wrong person.

5. The new girl will not make any friends unless she gets off her high horse.

a. The new girl will not form any friendships unless she stops behaving as if she is better than anyone else.

b. The newcomer won't be friends with anyone if she continues riding her horse alone in the open air.

c. The girl that has just arrived won't befriend anybody if she is always so shy.

$\mathrm{d}$. The new girl will become friends with no one unless she starts wearing more attractive clothes.

Complete the sentences with the correct word( $(s)$. bite."

1. "My boss wants to talk to me after work." - "Don't worry. His bark is his
a. better than
b. worse then
c. worse than
d. worst than

2. I can't waste time on this now. I have bigger ..........

a. fish to fry

b. geese to cook

c. goats to get

d. cats to kill

Write down the most appropriate idiomatic expression to complete the sentence.

1. A .......... told me that you have a birthday tomorrow.

2. The match has been cancelled because it's raining

Finally, the test questions with reference to Criterion V. (text creation) usually require students to compose a text with a limited number of words to explain the meaning of a selection of idioms and/or give examples illustrating their meaning and use. 
Explain the meaning of the idiomatic expression and describe a situation in about 100-150 words to illustrate its use.

1. If you get something straight from the horse's mouth, it means that you

2. If you say that your goose is cooked, you mean that

\section{Conclusion}

Based on feedback from students at the Faculty of Mathematics and Informatics at the University of Plovdiv, online practice tests are useful and entertaining. Students most often do the tests on their mobiles in time and place that is convenient for them. They claim that they like the variety of questions and that practice tests help them to remember idioms.

We are planning to continue incorporating self-study tests in the process of teaching English and enriching our database of test questions with idiomatic expressions with other components such as colors, parts of the body, food and drink, etc.

\section{Acknowledgement}

The authors wish to acknowledge the partial support of the National Program "Young Scientists and Postdoctoral Students" of the Ministry of Education and Science in Bulgaria.

\section{BIBLIOGRAPHY:}

Bloom, B. (1956)

Dunlosky, J. (2013)

Dunlosky, J., Rawson, K., Marsh, E., Nathan, M., Willingham, D. (2013)

Ivanova, V. (2014)

Ivanova, V., Terzieva, T. (2016)

Karpicke, J., Blunt, J. (2011)

Wyatt, R. (2006)
Taxonomy of Educational Objectives. Addison Wesley Publishing Company, 1956, pp. $44-58$.

Strengthening the Student Toolbox - In: Study Strategies to Boost Learning, American Educator. 12, FALL, pp. 12 - 21. https://www.aft.org/sites/default/files/periodicals/dunlosky.pdf (05.04.2020) Improving Students' Learning With Effective Learning Techniques: Promising Directions From Cognitive and Educational Psychology, pp. 4 58. <http://www.indiana.edu/ pcl/rgoldsto/courses/dunloskyimprovinglearn ing.pdf $>(05.04 .2020)$.

Use of Achievement Tests in the English Classes at the Distributed ELearning Centre. -In: Proceedings of the International Conference FROM DELC TO VELSPACE, Plovdiv, 26 - 28 March 2014, Plovdiv: Third Millennium Media Publications, pp. 167.

Criteria for the Construction of Tests for Language Assessment and Evaluation, Doctoral Conference in Mathematics and Informatics MIDOC: Sofia: St. Kliment Ohridski University Press, pp. 58 - 65.

Retrieval Practice Produces More Learning than Elaborative Studying with Concept Mapping, Science 331, 772, <http://www.physics.emory.edu/faculty/weeks//journal/karpickesci11a.pdf> (05.04.2020)

Check Your Vocabulary for Phrasal Verbs and Idioms. London: Great Britain, pp. 80.

\section{Appendix}

A list of some commonly used idioms and expressions with animals

(Think that one is) the bee's knees - to think you are very clever and important

(Wouldn't/can't) say boo to a goose - an expression used to describe someone who is very quiet and shy)

A little bird told me - an expression used for saying that you are not going to say who told you something 
A shaggy dog story - a long and often pointless story that is told as a joke and often ends in a very silly or unexpected way

As clean as a hound's tooth - very clean

As crooked as a dog's hind leg - very dishonest

As sick as a dog - very sick

Bark up the wrong tree - to choose the wrong course of action, to ask the wrong person (a hunting dog may make a mistake when chasing an animal and bark up the wrong tree)

Be a fly on the wall - to be able to see what people are doing without them noticing you

Be dressed up like a dog's dinner - when people are dressed in a way that shows they want to impress people, but their clothes are not suitable for the occasion

Be hen-pecked - criticized and given orders all the time by a wife or female partner

Be like a dog with two tails - to be very happy because something good has happened

Be running around like a headless chicken - trying to do a lot of things quickly without being sensible or calm about it

Be water off a duck's back - an expression used for saying that advice, warnings or insults do not affect someone

Better to be a live dog than a dead lion - it is better to be a live coward than a dead hero (this is from Ecclesiastes in the Bible)

Better to be the head of a dog than the tail of a lion - it is better to be the leader of a small group than a follower of a bigger one

Bird's-eye view - a good view of something from a high position

Call the dogs off or call off the dogs - to stop threatening or chasing or hounding someone

Cat got your tongue - unable to speak or think of something to say

Cat nap - a short sleep

Chicken out - to decide not to do something out of fear (usually just before)

Clam up - to become quiet suddenly

Cold fish - someone who is not very friendly

Copycat - someone who imitates or mimics someone else

Cut bait - either do something, or else get out of the way (you can say it to a person who is indecisive in order to motivate them to take one action or the other action)

Dark horse - someone with a secret, especially a secret ability, skill or achievement that surprises you when you discover it

Do the donkey's work - boring work that needs a lot of effort but has to be done as part of a job

Dog and pony show - something that you disapprove of because you think that it has only been organized to impress you

Dog days - very hot days

Dog in the manger - someone who prevents others from doing what they themselves do not want to do (in Aesop's Fables a dog that cannot eat hay lays in the hayrack and prevents the other animals from eating the hay)

Dog's breakfast - something or someone that looks extremely untidy, or something that is very badly done

Dog-eat-dog - ready or willing to fight and hurt others to get what one wants

Dressed up like a dog's dinner - wearing clothes which are inappropriate for the occasion or too formal

Dropping like flies - dying/giving up quickly

Eager beaver - a person who is excited about doing certain work deserves

Every dog has his day - everyone will have his chance or turn, everyone will get what he

Fat cats - people who receive too much money for the job they do 
Fight like cats and dogs - to argue and fight with someone (usually used for people who know each other)

Fishy - odd, suspicious

For donkey's ears - an extremely long time

else)

Get off one's high horse - to stop behaving as if he knows more or is better than anyone

Get one's goat - to annoy someone

Get something straight from the horse's mouth - information that comes from someone who is directly involved

Go to the dogs - to deteriorate, to become bad

Gone to the dogs - not as good at it was in the past

Have a bee in one's bonnet - to be very involved in something that you think is important, in a way that other people find annoying

Have a cat in hell's chance - to have no chance at all of doing something

Have a cow - get extremely upset (often over something minor)

Have a whale of a time - to have a lot of fun or worried

Have ants in your pants - a person can't stay still because they're very agitated, excited,

Have bigger fish to fry - to have more important things to do or think about

Hen night/party - a celebration for a woman who is about to get married, in which only her women friends take part

Hold your horses! - Wait a minute! Be patient!

Holy cow! - Wow, I'm surprised!

Horse around - play roughly

I could eat a horse! - an expression used for saying that you are very hungry

In a coon's age - in a very long time

In the doghouse - in disgrace or disfavor, in trouble

It cooked my goose (your goose is cooked) - to cause a lot of problems for someone, or spoil their plans

Kill two birds with one stone - to achieve two aims with one action

Kitty corner - in the diagonal direction

Lead a dog`s life - to lead a miserable life

Let sleeping dogs lie - do not make trouble if you do not have to

Let the cat out of the bag - to tell someone something that was supposed to be a secret

Like a fish out of water - to feel very uncomfortable in a particular situation or environment

Loan shark - someone who lends money to people and charges them a very high rate of interest

Look like a drowned rat - looking very wet and cold

Look like something that the cat dragged in - to have a very dirty or untidy appearance

Mad as a hornet - extremely angry

Make a beeline - go straight for something

Make a pig of oneself - to eat a lot of food

Make a pig's ear of something - to do something very badly

Monkey see, monkey do - silly/unintelligent people tend to copy each other's actions

Nest egg - money saved for the future

Not give a monkey's - to not care about something at all

On a wild goose chase - going after something that you are not likely to get, or a pursuit that is a waste of time because it is unlikely to succeed

One's bark is worse than one's bite - one's words are worse than one's actions 
One's tail between one`s legs - feeling beaten or humiliated (like a frightened or defeated dog as it walks away)

One-trick pony - the person has only one ability or good quality that he/she is known for, and doesn't have any other abilities

Pig out - eat a lot of something

Pig-headed - stupid and stubborn person (close-minded and inflexible)

Put on the dog - to dress or entertain in a luxurious and extravagant manner

Quit cold turkey - to stop completely

Rain cats and dogs - rain very hard

Rat race - fierce, competitive struggle for power, position, etc.

Ratbag - somebody who is unpleasant with other people

Red herring - a piece of information that draws attention away from the real facts of a situation (This idiom comes from the fact that a herring is a type of strong-smelling fish. If you are hunting with the help of a dog, and the dog smells a herring, it will be distracted by the strong smell and go in the wrong direction).

Rub (someone/someone's fur) the wrong way - to irritate someone (just as you would irritate a dog or cat if you rub their fur the wrong way) washroom)

See a man about a dog - to leave for some unmentioned purpose (often to go to the

Smell a rat - to be suspicious, or to think that someone is trying to trick you

Stag party - a social gathering for men exclusively, often involving entertainment considered unsuitable for women

Take the bull by the horns - to face a challenge or danger boldly; to attack a difficult or risky problem fearlessly

Talk the hind leg(s) off a donkey - to talk endlessly

The cat's meow - excellent, wonderful, really great

The cat's whiskers (the cat's pyjamas) - something considered to be outstanding

The elephant in the room - a problem or controversial issue that is too big to ignore, but that everyone tries to avoid talking about because it is embarrassing or will cause conflict

The hair of the dog that bit one - a drink of alcohol that one takes when recovering from a hangover

The lion's share of something - the biggest part or portion thing

The tail wagging the dog - a situation where a small part of something controls the whole

To hound (someone) - to pursue or chase someone, to harass someone

Top dog - the most important person in an organization

Turn tail - to run away from trouble or danger

Until the cows come home - for a very long time

Watching something like a hawk - watching extremely carefully

Weasels out of something - a person abandons their responsibility or commitment in a way that is sneaky or cowardly

What's good for the goose is good for the gander - an expression meaning that something that is good for one should be good for all

When pigs fly - something that is unlikely to happen (often said mockingly)

Work like a dog - to work very hard

Wouldn't hurt a fly - a person as very peaceful and non-violent

You can't teach an old dog new tricks - it is difficult for older people to learn new things 